\title{
A Study of Desiccant-Based Cooling and Dehumidifying System in Hot-Humid Climate
}

\author{
Maatouk Khoukhi
}

\begin{abstract}
The objective of this study is to investigate the feasibility of using desiccant cooling system as an alternative HVAC solution in buildings to achieve thermal comfort. This solution is more attractive when the solar energy is used to regenerate the desiccant wheel. An extensive experimental study has been performed in Tohoku University in Japan. A TRNSYS model of the desiccant cooling system combined with the heat wheel and heat source has been simulated and compared with the experimental data. The results of the simulation show that such system is feasible for cooling building in hot-humid climates.
\end{abstract}

Index Terms - Cooling, desiccant wheel, hot-humid climate.

\section{INTRODUCTION}

The building sector (commercial and residential) consume large amount of energy to support its operation and maintenance. Moreover, the large part of the energy demand by building is used to support indoor thermal comfort condition.

The provision of the building indoor thermal comfort conditions either through heating or cooling is done by the heat pumping system. These devices are called the mechanical vapor compression system [1]. Several researches are conducted to improve the system performance. However, the system still consumes a huge amount of energy. The main energy source of the mechanical vapor compression system is the electric energy from the grid line. In the Middle East, more than $70 \%$ of the building energy consumption is to support cooling [2]. In Europe, 10\% of the building sector energy consumption is like wise to support cooling demand [3]. In Hong Kong, $45 \%$ of the commercial building energy consumption is also for cooling [4]. In Japan, $3 \%$ of the building sector energy consumption is for cooling application [5]. It is expected that in tropical countries which are hot and humid, energy demand for cooling and dehumidification is very high [6].

Alternative air-conditioning (AC) system which utilizes alternative materials, process, and energy resources can largely reduce building energy consumption [7, 8]. Among the alternative AC systems the desiccant cooling systems which can be operated through direct thermal energy, are important options for building cooling.

The desiccant air conditioning system utilizes the

Manuscript received December 12, 2012; revised February 17, 2013 This work was supported in part by the SQU Internal Research Project IG/ENG/CAED/11/01

Maatouk Khoukhi is with Sultan Qaboos University, CAE Department, PO Box 33, Al Khoud 123, Sultanate of Oman (e-mail: mkhoukhi@ squ.edu.om). capability of desiccant materials in removing the air moisture content by sorption process. The sorption process (adsorption and absorption) is an interaction between the sorbent and sorbate molecule through intermolecular interaction [1]. Since desiccant materials have low concentration of water content, the air moisture content is attracted to the surface of the desiccant materials due to the moisture vapor pressure difference between the air and the desiccant surface. [1]. In order for the desiccant material to be used again, application of thermal energy is necessary to remove the moisture from the desiccant materials [1]. Fig. 1 shows the basic concept and diagram of the thermally activated desiccant cooling technologies.

\section{SOlid DesicCANT COOLING PRINCIPLES AND CONCEPT}

\section{A. Concept and Operation}

The solid desiccant cooling system is primarily based on the application of solid-based desiccant materials in controlling air moisture content. The sorption mechanism in the solid material is either through absorption or adsorption. Cooling by means of heat recovery, evaporative cooling or other means are applied to the system [1].

The solid desiccant material is the most widely used in desiccant cooling system. This is due to the simple handling of desiccant materials. The desiccant material is typically impregnated to the honeycomb designed wheels or of the cross-flow heat exchangers [1].

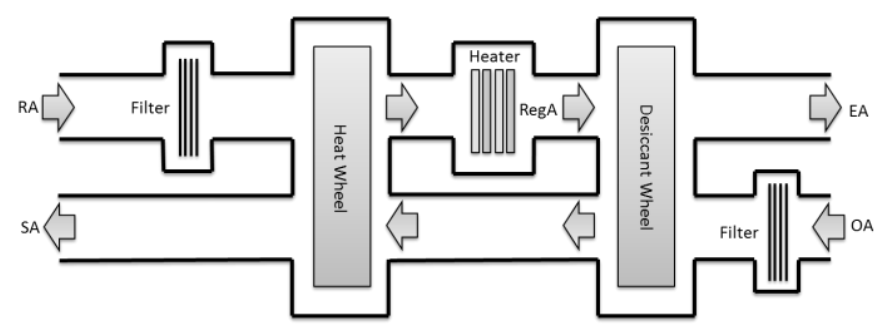

OA: outside air, SA: supply air, RA: return air, EA: exhaust air, RegA: regeneration air

Fig. 1. Basic concept of the desiccant cooling system.

\section{B. Development and Evolution}

The most common solid desiccant cooling system is composed of two wheels types or called the Munter Cycle shown in Fig.1. This is the basic design of the solid desiccant cooling system. The application of the desiccant wheel as the air dehumidifier has factors to be considered. It has been shown that the performance of the desiccant-based cooling 
and dehumidification system relies much on the desiccant material [9]. Kodama et al. shows that there is an optimal speed by which high sorption rate exists in the rotation desiccant wheel [10]. Gao et al. shows that the thickness of the desiccant material affects the sorption capacity [11]. At higher desiccant material thickness in the channel, higher sorption rate is attained due to more time to reach the steady state.

\section{EXPERIMENTAL FACILITIES}

Fig. 2 shows the physical set-up of the experimental facility. The two chambers A and B are used to simulate the outdoor and indoor air conditioning [12]. Chamber A has temperature range from $-10^{\circ} \mathrm{C}$ to $40^{\circ} \mathrm{C}$ with accuracy of $2 \%$. For chamber B, the operating temperature range is from $10^{\circ} \mathrm{C}$ to $40^{\circ} \mathrm{C}$ with accuracy of within $1 \%$. For both chambers the humidity could be varied depending on the needed conditions.

The main components of the desiccant based system consist of desiccant dehumidifier wheel, heat recovery wheel and heater. The performance of the whole system is dependent on the performance of its components. This task has been already conducted in the laboratory in Tohoku University [13] and the main results are presented below. The parameters considered for the evaluation were the rate of volumetric flow; the regeneration temperature and the wheel rotational speed (see Table I).

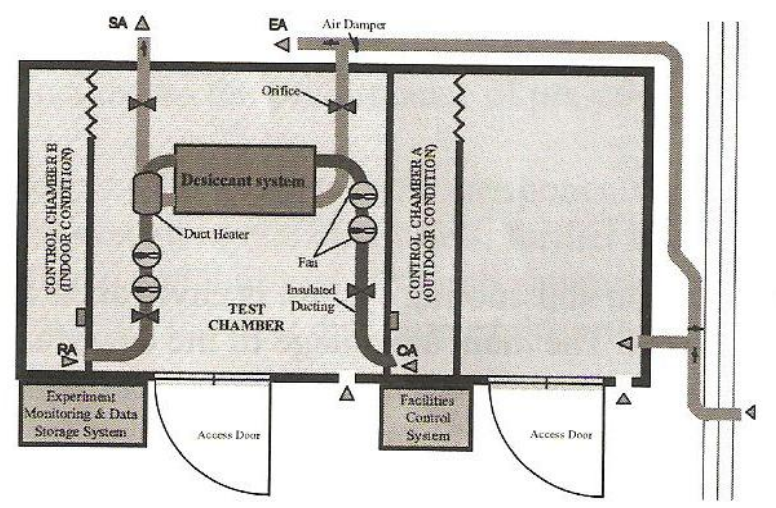

Fig. 2. Experimental facilities.

TABLE I: TARAMETERS USED TO EVALUATE THE PERFORMANCE OF THE DESICCANT COOLING SYSTEM

\begin{tabular}{|c|c|c|c|c|c|c|c|c|c|}
\hline $\begin{array}{lr}\text { Rate } & \text { of } \\
\text { volumetric } & \text { flow } \\
{\left[\mathrm{m}^{3} / \mathrm{hr}\right]} & \end{array}$ & \multicolumn{4}{|c|}{100} & \multicolumn{5}{|c|}{200} \\
\hline $\begin{array}{l}\text { Regeneration } \\
\text { temperature }\left[{ }^{\circ} \mathrm{C}\right]\end{array}$ & \multicolumn{3}{|c|}{60} & \multicolumn{3}{|c|}{70} & \multicolumn{3}{|c|}{80} \\
\hline $\begin{array}{l}\text { Wheel rotational } \\
\text { speed }[R P H]\end{array}$ & 5 & 10 & 20 & 25 & 30 & 35 & 40 & 50 & 60 \\
\hline
\end{tabular}

\section{MODELING AND SIMULATION}

The typical desiccant cooling air system as shown in Fig. 1 is an open heat driven cycle which comprises a desiccant wheel in tandem with a thermal wheel. A regeneration coil located in the return air stream drives the whole cycle.

The psychrometric chart shown in Fig. 3 illustrates the cooling/dehumidification process. During the summertime hot moist air at for example $35{ }^{\circ} \mathrm{C}$ and $21 \mathrm{~g} / \mathrm{kg}$ moisture content is drawn through the desiccant wheel so that it comes of at say $45^{\circ} \mathrm{C}$ and $18 \mathrm{~g} / \mathrm{kg}$ moisture content. The supply air stream then passes through the thermal wheel where it is sensibly cooled to say $30^{\circ} \mathrm{C}$.

On the return air side, air from the room space at for example, $31{ }^{\circ} \mathrm{C}$ and $24 \mathrm{~g} / \mathrm{kg}$ moisture content enters the thermal wheel. As the return air stream passes through the thermal wheel, it is sensibly heated. The air is then heated up to approximately $60{ }^{\circ} \mathrm{C}$ in order to regenerate the desiccant coil. It should be noted that in order to reduce system operation costs approximately $20 \%$ of the return air flow by-passes the regenerating oil and the desiccant wheel [14].

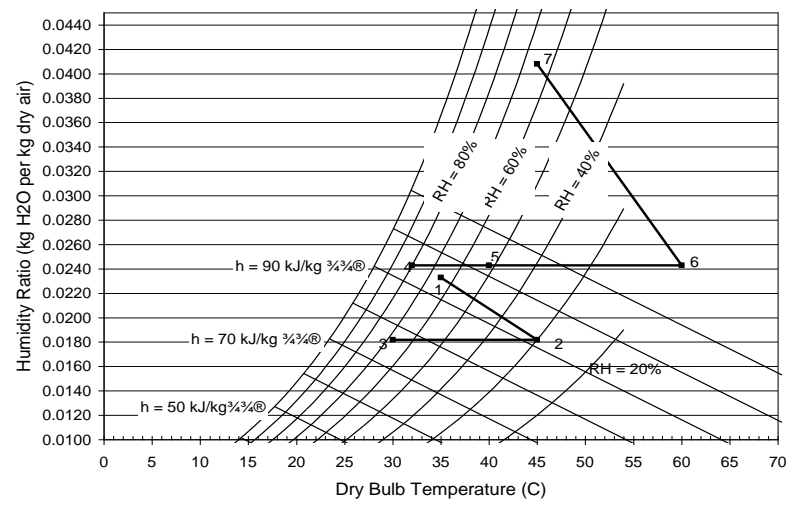

Fig. 3. Psychrometric chart showing a typical desiccant cooling process.

\section{A. Desiccant Wheel}

The considered desiccant wheel is a silica-gel coated wheel with $300 \mathrm{~mm}$ external diameter and $100 \mathrm{~mm}$ depth.
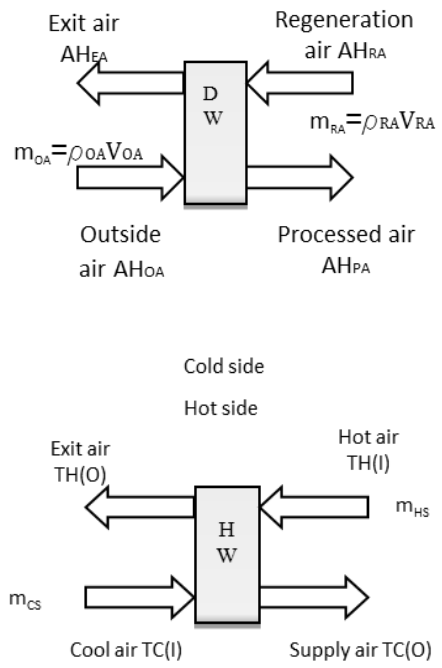

Fig. 4. The schematic diagram of the desiccant wheel (DW) and heat wheel (HW).

Fig. 4 shows the schematic diagram of the desiccant and heat wheels and the governing performances were based on National Renewable Energy Laboratory (NREL) testing manual [15]. The dehumidification performance of the desiccant wheel is based on moisture removal capacity or 
MRC given by

$$
M R C=m_{O A}\left(A H_{O A}-A H_{P A}\right)
$$

The amount of moisture removal capacity or sorption rate is the same at the regeneration side which is the moisture removal regeneration (MRR) expressed as

$$
M R R=m_{R A}\left(A H_{E A}-A H_{R A}\right)
$$

To evaluate the characteristic and performance of the experiment, the moisture mass balance (MBB) determined the quality of gathered data and thus the MBB is a checking factor and expressed as

$$
M M B=\frac{M R C}{M R R}
$$

$m_{O A}$ and $m_{R A}$ are the mass flow rates from the outside and regeneration side of the $\mathrm{DW}$ in $\mathrm{kg} / \mathrm{s}$, respectively. $A H_{O A}$, $A H_{P A}, A H_{E A}$ and $A H_{R A}$ are the absolute humidities of the outside air, processed air, exit air and regeneration air, respectively, $\mathrm{g} / \mathrm{kg}$ moisture content.

For acceptable accuracy of gathered data, the ratio of MBB should be within 0.5 to 1.5 .

\section{B. Heat Wheel}

The heat wheel is coated with silicone-acrylic compound. The physical appearance and dimension of the heat wheel is the same as the desiccant wheel. The main purpose of the heat wheel is for sensible heat recovery only

$$
E f f_{\text {Average }}=\frac{m_{C S}\left(T_{C(O)}-T_{C(I)}\right)+m_{H S}\left(T_{H(I)}-T_{H(o)}\right)}{2 m_{\text {Minimum }}\left(T_{H(I)}-T_{C(I)}\right)}
$$

Eff $f_{\text {Average }}$ is the average effectiveness of the heat wheel. The $\mathrm{m}_{\mathrm{CS}}$ and $\mathrm{m}_{\mathrm{HS}}$ are the mass flow rates (hot and cold sides), $\mathrm{kg} / \mathrm{s} . T_{C(\mathrm{I})}$ and $T_{C(\mathrm{O})}$ are the temperature of air in the cold side (inlet and outlet), ${ }^{\circ} \mathrm{C} . T_{H(\mathrm{I})}$ and $T_{H(\mathrm{O})}$ are temperature of air in the hot side inlet and outlet, ${ }^{\circ} \mathrm{C}$ and $m_{\text {Minimum }}$ is the minimum flow rate of either hot or cold side, $\mathrm{kg} / \mathrm{s}$.

\section{RESULTS AND DISCUSSION}

Fig. 5 shows the schematic diagram of the basic desiccant model which was under experimental investigation. This basic model is used for comparison with the experimental data obtained previously. Standard component such as DW, HW and heater were used to simulate the thermal behavior of the whole system under hot-humid climate using TRNSYS which is an abbreviation of Transient Simulation.

TRNSYS is a simulation environment and an open modular structure for the transient simulation of system used to validate new energy concepts. A TRNSYS project is typically set up by connecting components graphically in the simulation studio [16]. The two effectiveness value of the DW proposed by Banks which is discussed in TRNSYS manual have been used in the simulation.

The basic model of the DW combined with HW and heater for the DW regeneration shown in Fig. 4 has been validated against the experimental published data [13]. Table 2 shows the comparison between the experimental data and the simulated ones.

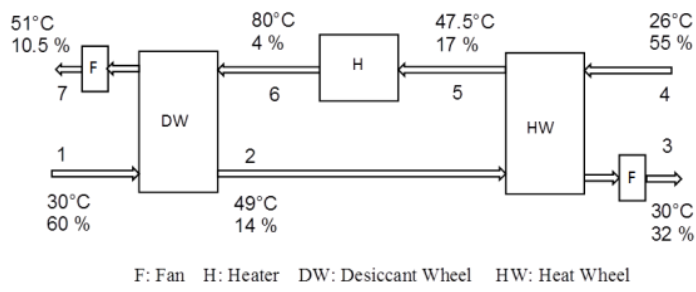

Fig. 5. Simulation result of the basic desiccant cooling system.

The air conditions for the outdoor air (point 1) are set at value of $30^{\circ} \mathrm{C}$ and $60 \% \mathrm{Rh}$. The volumetric flow rate is 120 $\mathrm{m}^{3} / \mathrm{h}$. the return air (point 4 ) is set at value of $26^{\circ} \mathrm{C}$ and $55 \% \mathrm{Rh}$ and flow rate of $120 \mathrm{~m}^{3} / \mathrm{h}$. The result of the simulation shows that the DBT and Rh are within the accepted range compared with the experimental ones. The differences are mainly due to the initial value of some intrinsic parameters of the model such as the DW and HW effectivenesses, which must be thoroughly investigated and adjusted in the future.

The basic model of the desiccant cooling system is limited in term of input data of the DBT. Indeed, for high DBT, TRNSYS does not have the capability to converge towards the solution. Therefore, a pre-cooling system using indirect evaporative cooler IEC will solve the problem. The Desiccant cooling system with IEC is shown in Fig. 6. It can be seen that the Rh of the supply air (state 4 ) decreases by 24 $\%$, while the DBT decreases by $9 \%$ compared with the outdoor conditions. By adding direct evaporative cooler DEC as shown by Fig. 7 the DBT drops to $29^{\circ} \mathrm{C}$ and Rh rises to 59 $\%$ which are considered as appropriate indoor condition for thermal comfort.

TABLE II: EXPERIMENTAL AND SIMULATION RESULTS

\begin{tabular}{llccccccc}
\hline & 1 & 2 & 3 & 4 & 5 & 6 & 7 \\
\hline $\begin{array}{l}\text { DBT } \\
{\left[{ }^{\circ} \mathrm{C}\right]}\end{array}$ & $\begin{array}{l}\text { Experim } \\
\text { entation }\end{array}$ & 30.8 & 59.2 & 33.5 & 26.1 & 52.6 & 80 & 51.9 \\
\hline $\begin{array}{l}\text { DBT } \\
{\left[{ }^{\circ} \mathrm{C}\right]}\end{array}$ & $\begin{array}{l}\text { Simulati } \\
\text { on }\end{array}$ & 30 & 49 & 30 & 26 & 47.5 & 80 & 51 \\
\hline $\begin{array}{l}\mathrm{RH} \\
{[\%]}\end{array}$ & $\begin{array}{l}\text { Experim } \\
\text { entation }\end{array}$ & 58.5 & 9.1 & 35.3 & 55.5 & 13.3 & 3.9 & 20.1 \\
\hline $\begin{array}{l}\text { RH } \\
{[\%]}\end{array}$ & $\begin{array}{l}\text { Simulati } \\
\text { on }\end{array}$ & 60 & 12 & 32 & 55 & 17 & 4 & 10.5 \\
\hline$\%$ & DBT & 2.5 & 17.2 & 10.4 & 0 & 9.7 & 0 & 1.7 \\
$\begin{array}{l}\text { Differe } \\
\text { nce }\end{array}$ & RH & 2.5 & 24.1 & 9.3 & 1 & 21.7 & 2.5 & 47.7
\end{tabular}

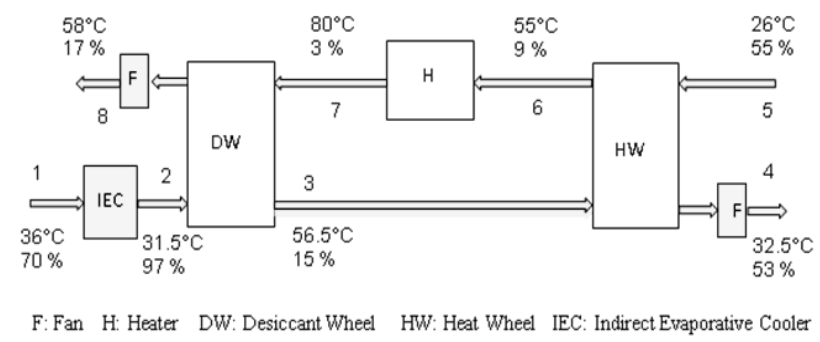

Fig. 6. Schematic diagram of the standard desiccant cooling system with pre-cooling. 


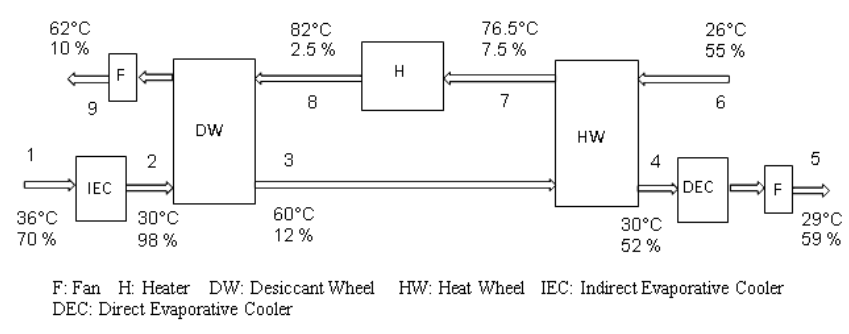

Fig. 7. Schematic diagram of the standard desiccant cooling system with pre-cooling and DEC.

\section{CONCLUSION}

The desiccant cooling system presented in this paper which combines the desiccant wheel with heat wheel can be a suitable solution for hot-humid climate. The basic model by means of TRNSYS has been validated against the experimental data obtained from Tohoku University in Japan.

Combining the basic desiccant model with IEC and DEC allows reducing significantly the DBT to $29^{\circ} \mathrm{C}$ and keeping $\mathrm{Rh}$ within the accepted value $59 \%$ considering hot-humid outside climate at $36^{\circ} \mathrm{C}$ and $70 \%$.

The performance of the desiccant cooling system will be studied more for further improvements. One of these improvements is to combine with the desiccant cooling system a solar air heating system for the DW regeneration.

\section{ACKNOWLEDGMENT}

The author gratefully acknowledges Tohoku University for the experimental data provided for this research.

\section{REFERENCES}

[1] N. Enteria and K. Mizutani, "The role of the thermally activated desiccant cooling technologies in the issue of energy and environment," Renewable and Sustainable Energy Reviews, vol. 15, pp. 2095-2122, 2011.

[2] H. El-Dessouky, H. Ettouney, and A. Al-Zeefari, "Performance analysis of two-stage evaporative coolers," Chemical Engineering Journal, vol. 102, pp. 255-266, 2004.

[3] M. Kolokotroni and A. Aronis, "Cooling-energy reduction in air-conditionined offices by using night ventilation," Applied Energy, vol. 63 , pp. 241-253, 1999.
[4] Z. M. Zain, M. N. Taib and S.M.S. Baki, "Hot snd humid climate: prospect for thermal comfort in residential building," Desalination, vol. 208, pp. 261-268, 2007.

[5] S. Murakami et al. "Overview of energy consumption and GHG mitigation technologies in the building sector of Japan," Energy Efficiency, vol. 2, pp. 179-194, 2009.

[6] N. Wrong and S. Li, "A study of the effectiveness of passive climate control in naturally ventilated residential buildings in Singapore," Building and Environment, vol. 42, pp. 1395-1405, 2007

[7] Residential and commercial buildings, Climate change mitigation, Intergovernmental panel on climate change, New York: cambrige University, 2007.

[8] IPCC Scoping meeting on renewable energy resources. (January 20-25, 2008). Luberck, Germany. [Online]. Available: http://www.ipcc.ch/pdf/supporting-material/proc-renewables-luberck. pdf.

[9] T. Kang and I. Maclaine-cross, "High performance solid dessicant, open cooling cycles," ASME Transactions: Journal of Solar Energy Enginering, vol. 111, pp. 176-183, 1989

[10] A. Kodama, T. Hirayama, M. Goto, T. Hirose, and R. Critoph," The use of psychrmetric charts for the optimization of a thermal swing desiccant wheel, vol. 21, pp. 1657-1674, 2001

[11] Z. gao, V. Mei, and J. Tomlinson, "Theoretical analysis of dehumidification precess in a desiccant wheel," Heat Mass Transfer, vol. 28, pp. 1033-1042, 2005.

[12] M. Khoukhi and A. J. Shahad, "Feasibility of using desiccant cooling system in hot-humid region," APPEEC 2012, March 27-29, Shanghai, China.

[13] N. Enteria, H. Yoshino, R. Takaki, A. Satake, A. Mochida, M. Khoukhi, R. Yoshie, T. Mitamura, and S. Baba, "The experimental works and some parametric investigations of thermally activated desiccant cooling system," in Proc. of Clima 2007 WellBeing Indoors.

[14] CIBSE. "C" Guide. Chartered Institute of Building Services Engineers, 1980.

[15] S. Slakay and R. Ryan, Desiccant Wheel Dehumidification Test Guide, National Renewable.

[16] TRNSYS 16, Solar Energy Laboratory, University of WisconsinMadison, USA.

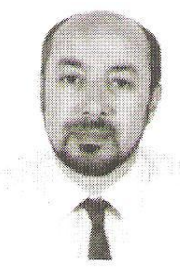

Maatouk Khoukhi earned his doctorate in Mechanical Engineering from Tohoku University-Japan. Dr. Maatouk Khoukhi has a long record of academic and industrial experience in solar energy, thermal sciences and building sciences. Currently, he is A/Professor at Sultan Qaboos University, Oman. His research works have been supported by several grants from Samsung, NEDO, and universities' internal and external grants. The total budget of his projects exceeds 3.5 Million USD. He has published more than 50 journal and conference papers and he is a reviewer for several journals in his field of specialization. 